\title{
A fire-driven shift from forest to non-forest: evidence for alternative stable states?
}

\author{
Michael-Shawn Fletcher, ${ }^{1,2,3,5}$ Sam W. Wood ${ }^{4}$ and Simon G. Haberle ${ }^{2}$ \\ ${ }^{1}$ Department of Resource Management and Geography, University of Melbourne, Parkville, Victoria 3010 Australia \\ ${ }^{2}$ Archaeology and Natural History, College of Asia and the Pacific, The Australian National University, Canberra 0200 Australia \\ ${ }^{3}$ Institute of Ecology and Biodiversity, University of Chile, Santiago, Chile \\ ${ }^{4}$ School of Plant Science, University of Tasmania, Private Bag 55, Hobart, Tasmania 7001 Australia
}

\begin{abstract}
We test the validity of applying the alternative stable state paradigm to account for the landscape-scale forest/non-forest mosaic that prevails in temperate Tasmania, Australia. This test is based on fine-scale pollen, spore, and charcoal analyses of sediments located within a small patch of non-forest vegetation surrounded by temperate forest. Following nearly 500 years of forest dominance at the site, a catastrophic fire drove an irreversible shift from a forested Cyperaceae-Sphagnum wetland to a non-forested Restionaceae wetland at ca. 7000 calibrated (cal) yr BP. Persistence of the non-forest/ Restionaceae vegetation state over 7000 years, despite long fire-free intervals, implies that fire was not essential for the maintenance of the non-forest state. We propose that reduced interception and transpiration of the non-forest state resulted in local waterlogging, presenting an eco-hydrological barrier to forest reestablishment over the succeeding 7000 years. We further contend that the rhizomatous nature of the non-forest species presented a reinforcing eco-physical barrier to forest development. Our results satisfy a number of criteria for consideration as an example of a switch between alternative stable states, including different origin and maintenance pathways, and they provide insights into the role of threshold dynamics and hysteresis in forest-non-forest transitions.
\end{abstract}

Key words: alternative stable states; Australia; fire; forest; hysteresis; non-forest; paleoecology; regime shift; Tasmania.

\section{INTRODUCTION}

Large sudden shifts in ecosystem states, such as sudden shifts between forest and grassland, occur when an ecological system crosses a threshold (Scheffer et al. 2001, Scheffer and Carpenter 2003). Such shifts in ecosystem states can have serious ramifications for ecosystem functioning; for example, forests have a substantially higher carbon storage potential relative to grasslands (Casini et al. 2009). The understanding of how and why these shifts occur is, thus, a critical endeavor. Triggers for shifts across ecological thresholds include large external perturbations, small incremental environmental changes, and internal feedbacks (Scheffer and Carpenter 2003). Following a catastrophic regime shift, a system may return to its original state or the system may settle around a new state (Scheffer and Carpenter 2003). This latter situation may arise from the existence of alternative stable ecosystem states.

The model of alternative stable states is often invoked to account for the persistence of different species assemblages within the same environment

Manuscript received 14 October 2012; revised 22 October 2013; accepted 15 November 2013; final version received 11 December 2013. Corresponding Editor: F. S. Hu.

5E-mail:msfl@unimelb.edu.au
(Petraitis and Latham 1999). Shifts between stable ecosystem states occur when (1) a critical threshold is crossed that results in the removal of species required for the self-maintenance of one state, (2) a species that initiates a switch to an alternative state arrives, and (3) the new species assemblage is capable of self-maintenance for more than one generation (Connell and Sousa 1983, Petraitis and Latham 1999, Scheffer et al. 2001, Scheffer and Carpenter 2003). In terrestrial vegetation systems, alternative stable states often manifest spatially as sharp transitions in an assemblage/physiognomic state (Wilson and Agnew 1992), while temporal shifts may manifest as historical discontinuities in vegetation communities that may be represented as jumps in time-series data (Scheffer and Carpenter 2003). Despite the recent widespread application of the alternative stable state model to a range of natural systems (e.g., Scheffer et al. 1993, Scheffer and Carpenter 2003, Petraitis and Dudgeon 2004, Warman and Moles 2009, Odion et al. 2010, Hirota et al. 2011, Mayer and Khalyani 2011), demonstrating that the same site conditions can support alternative states in terrestrial vegetation systems is far from easy (Petraitis and Latham 1999, Schröder et al. 2005, Odion et al. 2010). A complicating factor in terrestrial vegetation systems is demonstrating stability: the ability of the vegetation state to maintain itself through more than 
one generation (Connell and Sousa 1983, Peterson 1984). This problem is most salient in long-lived vegetation systems, such as forests and shrublands, where generational times are long. Such systems require novel approaches to gathering the data needed to understand the underlying mechanisms governing their apparent stability (e.g., Warman and Moles 2009, Odion et al. 2010, Hirota et al. 2011, Jeffers et al. 2011). Here, we use paleoecology to reconstruct a regime shift between temperate forest and non-forest vegetation states in the southern hemisphere.

Mosaics of forest, savanna, and grasslands have been used as a model system for exploring the efficacy of the alternative stable states model for terrestrial landscapes (Hirota et al. 2011, Lehmann et al. 2011, Mayer and Khalyani 2011, Staver et al. 2011). In this system, vegetation transitions between three states (forest, savannah, and grassland) according to feedback mechanisms related to rainfall and fire (Mayer and Khalyani 2011). Drawing on the state and transition concepts put forward for the forest-savannah-grassland system and the early work of Jackson (1968) in Tasmania, Wood and Bowman (2012; see also Wood et al. 2011a,b) framed the vegetation landscape of temperate southwest Tasmania in the alternative stable states framework. This system has four vegetation states: rain forest, eucalypt forest, sclerophyll shrubs, and moorland. Rainforest and eucalypt forest in southwest Tasmania are sensitive to frequent fires, but they produce a considerable amount of fuel that is flammable when dry (particularly eucalypt forest). The forest state is maintained by an infrequent fire regime (70-400 year fire-return interval for eucalypt forest and $>400$ year fire-return interval for rainforest) that has a twofold effect: (1) the establishment of slower growing trees relative to non-forest species and (2) the accumulation of soil nutrients that are essential for forest development in this extremely oligotrophic region (Jackson 1968, Pyrke and Marsden-Smedley 2005, Bowman and Wood 2009, Wood and Bowman 2012). These positive feedbacks between fire, vegetation, and soil characteristics engender an inertia to change in these vegetation states, but repeat fires or high severity fires can trigger transitions between vegetation states.

While there is evidence for fire-vegetation-soil feedbacks that reflect the mechanisms of self-maintenance in this system (Wood and Bowman 2012), the factors leading to the establishment of these alternative vegetation states remain untested (i.e., the problem of "origin" [Petraitis and Latham 1999]). Only one study unequivocally documents the establishment of nonforest vegetation in place of forest in this region, but the factors leading to the establishment of non-forest at that site (the origin) are unknown (Ellis and Thomas 1988). Moreover, while fire clearly plays a key role in this vegetation landscape, relatively little attention has been given to the potential role of other factors, such as hydrology, in maintaining alternate vegetation states in this system (Pemberton 1989). Anecdotal information on the role of hydrology in temperate forest-non-forest dynamics can be drawn from other high-rainfall temperate regions, where permanent transformations from forest to non-forest are observed after forest removal and are explained by reduced transpiration rates under forest canopies relative to non-forest (Díaz and Armesto 2007). The altered transpiration regime results in soil waterlogging and excludes tree seedling reestablishment (Díaz and Armesto 2007). While not explicating a mechanistic pathway, Pemberton (1989) invoked hydrology as a possible factor in the apparent inability of forest to encroach upon some non-forest patches in the humid landscape of Tasmania. However, the influence of hydrology in this system has been largely ignored.

Here, we examine the roles of fire and hydrology in the origin and maintenance of forest and non-forest vegetation states by reconstructing vegetation and fire history over the last 7500 years of a small ( $<18$ ha) moorland (non-forest) patch surrounded by forest on the Gog Range in Tasmania, Australia. The plateau of the Gog Range is characterized by a series of discrete non-forest patches nested within a larger forest matrix (Fig. 1). Paleoecological research from within a patch of moorland on the Gog Range reveals that at least parts of the plateau that now host moorland were occupied by forest during the mid Holocene, with fire implicated in the permanent transition from forest to non-forest (Webb et al. 1994). We focus on multi-decadal scale dynamics close to a forest-non-forest boundary and specifically ask: (1) What are the extrinsic factors leading to the establishment of non-forest in place of forest in this temperate system (i.e., the problem of origin)? (2) Do forest and non-forest represent alternative stable states in this system? and (3) What are the mechanisms of self-maintenance of vegetation states in this system?

\section{Methods}

To reconstruct vegetation and fire history over the last 7500 years on the Gog Range $\left(41^{\circ} 30^{\prime} 28^{\prime \prime} \mathrm{S}, 146^{\circ} 23^{\prime} 5^{\prime \prime} \mathrm{E}\right)$, we retrieved a 94-cm core from Granta Pools using a Dsection corer. The Gog Range is a low $(\sim 750 \mathrm{~m}) 13-\mathrm{km}$ range that is crested by a flat narrow plateau. The climate is humid, with an annual winter dominant rainfall of $1200 \mathrm{~mm}$. The Granta Pools are surrounded by a $<18$-ha patch of non-forest moorland (one of many that line the plateau), and tall Eucalyptus forests with an understory of mesophyte wet forest and rainforest species (temperate eucalypt/wet sclerophyll forest) cloak the northern and southern slopes of the Gog Range, growing to within $120 \mathrm{~m}$ of Granta Pools (Fig. 1). The site occupies a shallow depression in the Ordovician conglomerate bedrock that has filled in with organic sediments. Ordovician conglomerate, along with Precambrian quartzite, are low nutrient yielding and highly resistant rock types that dominate the geology of west 
and southwest Tasmania (Woodward et al. 1993), giving rise to the extreme oligotrophy that characterizes this landscape.

To enable the vegetation and fire reconstruction, we analyzed contiguous $1 \mathrm{~cm}$ thick sediment samples from the Granta Pools core for pollen, spores, and charcoal following standard protocols (Faegri and Iversen 1989, Whitlock and Larsen 2001). Pollen percentages were calculated with two sums: one that includes all taxa and the other that includes terrestrial taxa only. Pollen analysis is a powerful tool for vegetation reconstruction that relies on an appreciation of the relationship between pollen deposition and vegetation (Bunting 2003). Of particular relevance to the present study are the well-established depositional characteristics of wetland and arboreal pollen types: wetland pollen types are rarely transported far from their source plants and are good indicators of local wetland dynamics (e.g., Bunting 2003), while arboreal pollen types can be grossly over represented in pollen spectra relative to their presence in the vegetation. Critically, all key tree pollen types in Tasmania are over represented in the modern pollen rain (Macphail 1979, Fletcher and Thomas 2007).

Fletcher and Thomas (2007) conducted a thorough numerical analysis of pollen-vegetation relationships in western Tasmania that is vital for interpreting pollen data in this region in terms of vegetation. The key relevant findings of that study for the present paper are summarized here. The principal rain forest species in Tasmania, Nothofagus cunninghamii, can comprise up to $50 \%$ of the terrestrial pollen sum of pollen spectra from non-forest vegetation. Eucalyptus, the dominant tree type in the study area, can contribute more than $30 \%$ of the terrestrial pollen sum at sites where Eucalyptus species are absent from the local vegetation. Likewise, the other dominant arboreal taxon at Granta Pools, Pomaderris apetala, can register values higher than $20 \%$ of terrestrial pollen sums at sites where it is absent from the local flora (Fletcher and Thomas 2007). In contrast, non-forest taxa (Gymnoschoenus sphaerocephalus, Melaleuca, and Leptospermum/Baeckea) are uniformly underrepresented in the modern pollen rain of Tasmania and are rarely encountered in the pollen spectra of sites from which they are absent (Fletcher and Thomas 2007). Indeed, the key moorland plant species, Gymnoschoenus sphaerocephalus, registers pollen values as low as $5 \%$ at sites where it composes almost $60 \%$ of the local vegetation (Fletcher and Thomas 2007).

The accumulation rates of pollen and spores (PAR) and charcoal (CHAR), which reveal changes in the actual influx of pollen or charcoal independent of variables other than time, were calculated using ages interpolated to each sample level based on an agedepth model derived from four radiocarbon ages. Radiocarbon ages were converted to calibrated years (cal yr BP) using the southern hemisphere calibration curve (McCormac et al. [2004]; see Fig. 5 and Table 1). Detrended correspondence analysis (DCA) was used to identify compositional trends in the (relative) terrestrial pollen dataset using PCOrd 4.27 (McCune and Mefford 1999). To reconstruct the local fire history, we employed CharAnalysis software (Higuera et al. 2009). The CHAR data was interpolated to the median sample resolution (63 yr/sample) for the analysis of CHAR peak frequency. Charcoal peaks, a proxy for local fire episodes (Higuera et al. 2010), were identified as the positive residuals exceeding a locally fitted CHAR background model (400-year window).

\section{Results}

In this section, we present a detailed analysis of the period between ca. 7500 and $6500 \mathrm{cal}$ yr BP, highlighting the critical transition between forest and non-forest at the site. The dominant pollen and spores between ca. 7400 and 7000 cal yr BP are Cyperaceae and Sphagnum (aquatic/wetland component) and Eucalyptus and Pomaderris (terrestrial component). Peak CHAR values at ca. 7000 cal yr BP coincide with a spike in Botryococcus, a replacement in the wetland flora of Cyperaceae by Restionaceae, and in the terrestrial flora by Leptospermum/Beackea, G. Sphaerocephalus, and Melaleuca. These latter taxa remain dominant for the remainder of the record.

Rapidly accumulating peat occurred under a Cyperaceae-Sphagnum wetland and a forest dominated by Pomaderris and other forest elements between ca. 7400 and 7000 cal yr BP (Fig. 2). This 400-year phase documents a period when the temperate eucalypt forest that presently cloaks the slopes of the Gog Range occupied the currently non-forested patch of vegetation at the Granta Pools site. Our results mirror a lower resolution pollen record from within moorland on the Gog Range plateau (Webb et al. 1994). Together these results imply that significant portions of, if not the entire, summit plateau hosted temperate eucalypt forest through this time. Peak CHAR values occur at ca. 7000 cal yr BP (Fig. 3c) coincident with a major, abrupt, transition in the terrestrial and wetland systems (Figs. 2 and $3 b)$. Cyperaceae replaced Restionaceae as the dominant wetland taxon around 7000 cal yr BP, punctuated by a brief (33-year) Botryococcus (a colonial algae) phase between ca. 7060-7000 cal yr BP (Fig. 2). This brief algal phase is coincident with peak CHAR values and a marked drop in Sphagnum (Fig. 2b), suggesting the destruction of the CyperaceaeSphagnum wetland and the transitory development of areas of open water prior to the colonization of the site by Restionaceous species. A shift from high arboreal pollen values (Fig. 2d) to high values of non-forest moorland/scrub taxa (Gymnoschoeunus sphaeocephalus, Melaleuca, and Leptospermum/Beackea) also begins at ca. 7000 cal yr BP (Fig. 2e), culminating in an arboreal minimum at ca. 6800 cal yr BP and a maximum of 


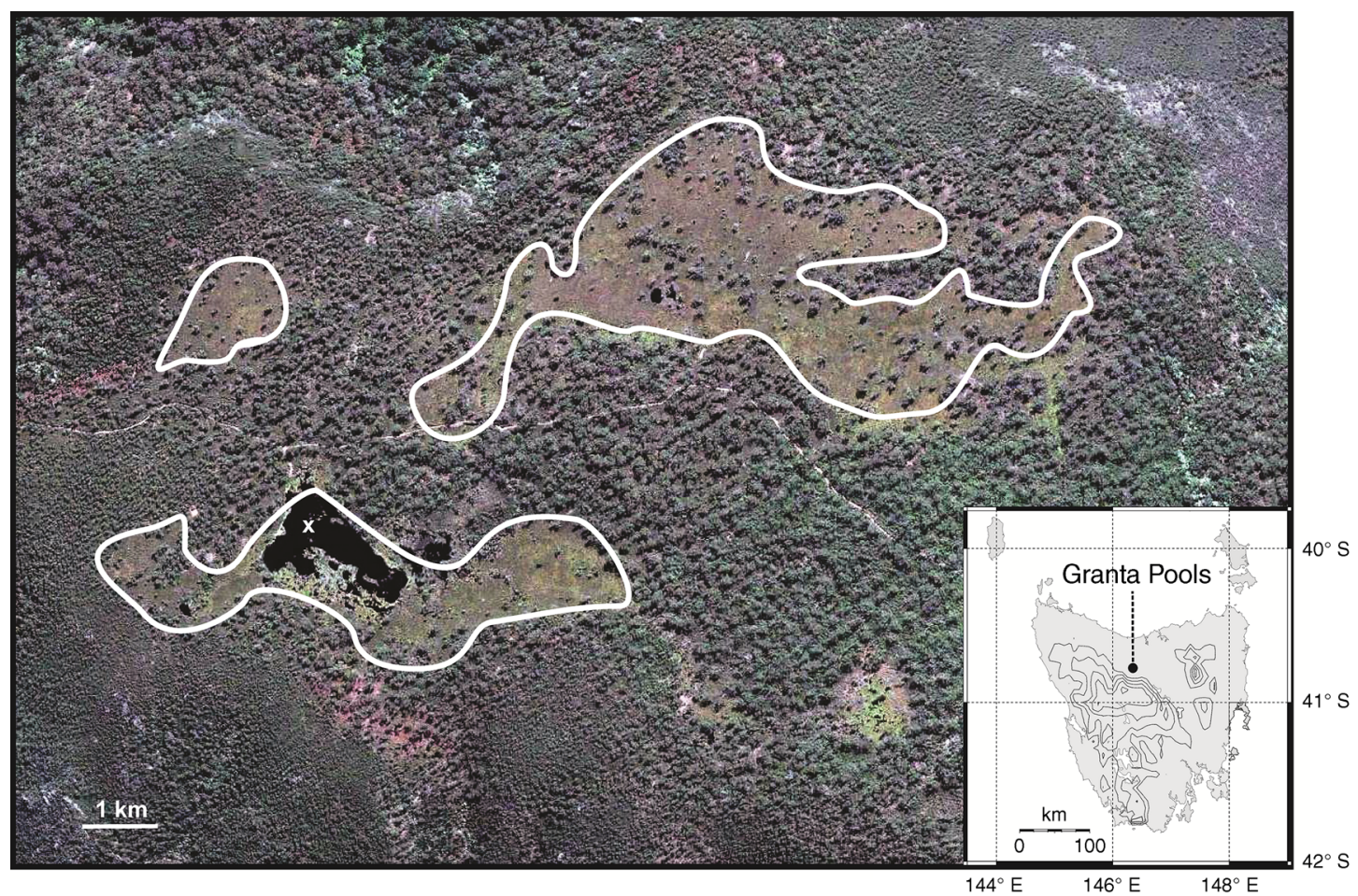

FIG. 1. An image of the Gog Range plateau showing the coring site within Granta Pools and highlighting (bordered in white) the non-forest vegetation on the plateau. The X marks the location of the coring site within Granta Pools. The location of the core site in Tasmania is shown in the inset.

moorland/scrub taxa between ca. 6650 and 6600 cal yr BP (Fig. 2d, e).

The most salient feature of our data is the abrupt and unidirectional nature of the transition between forest and non-forest at ca. $7000 \mathrm{cal}$ yr BP (Fig. 3b). The DCA of the terrestrial pollen dataset reveals two statistically significant populations along the main axis of variation (DCA Axis 1) marking this transition (Figs. 3c and 4): a population of forest taxa prior to the transition and a population of moorland/scrub taxa afterwards (Fig. 4). Following this transition, the non-forest state displays a remarkable degree of stability throughout the record (Fig. 3). The stability of the non-forest state occurs, despite more than 700 years elapsing before another local fire episode at the site and despite prolonged periods low fire episode frequency and between 4000 and 1000 cal yr BP (Fig. 3).

\section{Discussion}

\section{Forest-non-forest transition}

Various feedback mechanisms (Fig. 5) may have contributed to the changes observed between ca. 7500 and $6500 \mathrm{cal} \mathrm{yr} \mathrm{BP}$ at Granta Pools, and to the maintenance of the stable vegetation states (sensu Wood and Bowman 2012). Each vegetation community may modify the rate of fuel accumulation and fuel characteristics (and therefore fire frequency), soil nutrient capital, and light environment in a direction that enhances its own growth and survival, and simultaneously hinders or constrains other vegetation types (Fig. 5b). The results of the present analysis suggest an alternate self-maintenance pathway in this system: ecohydrology (Fig. 5c). High transpiration rates under forest canopies in high rainfall regions facilitate the

TABLE 1. Radiocarbon dating results.

\begin{tabular}{cccccc}
\hline \hline Lab code & $\begin{array}{c}\text { Depth } \\
(\mathrm{cm})\end{array}$ & $\begin{array}{c}\text { Radiocarbon age } \\
\left({ }^{14} \text { C years }\right)\end{array}$ & $\begin{array}{c}\text { Median probability } \\
(\text { cal yr BP })\end{array}$ & $\begin{array}{c}\text { Lower range } \\
(\text { cal yr BP })\end{array}$ & $\begin{array}{c}\text { Upper range } \\
(\text { cal yr BP })\end{array}$ \\
\hline S-ANU4630 & 19 & 1590 & 1429 & 1332 & 1530 \\
S-ANU4631 & 42 & 4675 & 5400 & 5089 & 5467 \\
S-ANU4632 & 67 & 6185 & 6980 & 6907 & 7160 \\
S-ANU4633 & 89 & 6470 & 7347 & 7254 & 7429 \\
\hline
\end{tabular}

Notes: Upper and lower ranges are based on 2-sigma error ranges. Calibrations (cal yr BP) are based on the southern hemisphere calibration curve of McCormac et al. (2004). 


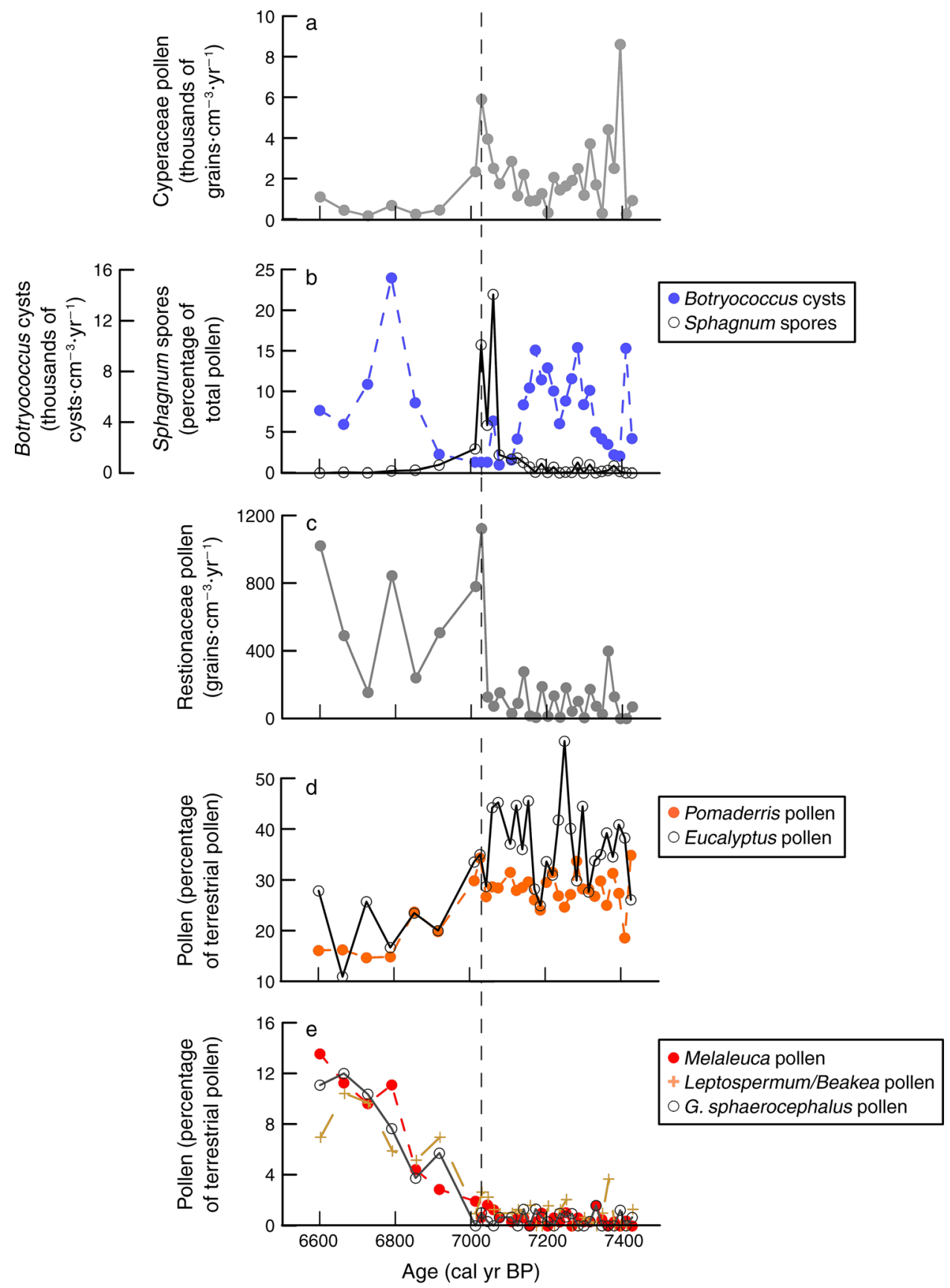

FIG. 2. Pollen and spore data from Granta Pools from 7500 to 6600 calibrated (cal) yr BP. The dashed vertical line indicates the critical transition between forest and non-forest at the site.

aeration of soils that are susceptible to waterlogging, which can inhibit tree establishment (Díaz and Armesto 2007). Eucalyptus species exhibit remarkably high evapo-transpiration rates (Sharma 1984), and the persistence of temperate eucalypt forest at Granta Pools under a wet climate regime prior to $7000 \mathrm{cal} \mathrm{yr} \mathrm{BP}$ is consistent with high transpiration rates under forest vegetation. Temperate eucalypt forest in Australia is sensitive to frequent fire, but produces a considerable amount of flammable fuel and is maintained by an infrequent (70-400-year fire-return interval) fire regime. While able to persist as a distinct vegetation state for millennia (Macphail 1984), under certain conditions (dry summer-autumn), temperate eucalypt forest is a highly flammable vegetation type with a high fuel load (Bradstock 2010). The fire at ca. $7000 \mathrm{cal} \mathrm{yr} \mathrm{BP} \mathrm{at}$ 

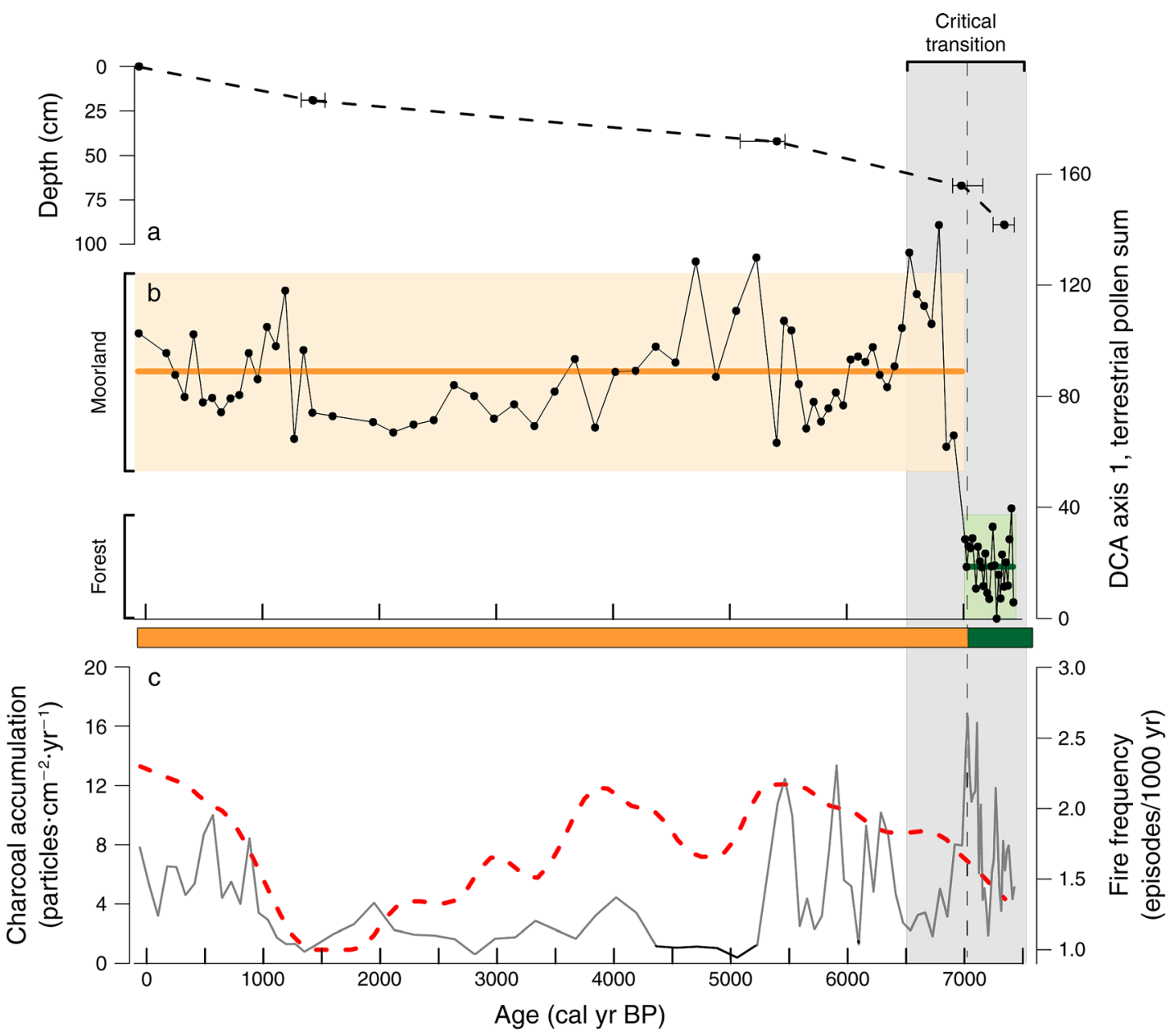

FIG. 3. A time series plot of environmental data over the last 7500 years pertinent to Granta Pools. (a) The linear age-depth curve based on four radiocarbon ages. Error bars indicate the 2-sigma error range of the calibrated radiocarbon ages. (b) Ordination axis scores from a detrended correspondence analysis (DCA axis 1) of the terrestrial pollen data set from Granta Pools (the orange [green] horizontal bar indicates the mean axis value for the non-forest [forest] vegetation states, while the shaded area indicates two standard deviations from the mean). (c) Charcoal accumulation (gray solid line) and fire episode frequency (red dashed line) at Granta Pools. The dashed vertical line indicates critical transition between forest and non-forest at the site.

Granta Pools had a catastrophic local impact, destroying the then extant forest system and resulting in an immediate transition to non-forest vegetation at the site (Figs. $3 b$ and $5 c$ and $d$ ).

The destruction of the forest vegetation and Cyperaceae-Sphagnum wetland by fire, facilitated the invasion of the site by Restionaceae species and, subsequently, by the rhizomatous sedge G. sphaerocephalus. Restionaceae species commonly occupy the most waterlogged areas in Tasmanian non-forest vegetation (moorland in this case) and are the principal peat-forming species in many ponds within moorland vegetation. Elsewhere in the oligotrophic systems of Tasmania, the resilience of widespread tracts of non-forest vegetation appears to be related to a complex suite of feedbacks related to a high frequency of fire and interactions of fire with soil nutrients (Fig. 5b; reviewed by Wood et al. [2011]).
However, the low levels of charcoal since the establishment of non-forest vegetation at Granta Pools appear to discount frequent fire as a factor in the maintenance of this system.

We suggest two additional feedback mechanisms that contribute to the inability of forest species to invade the non-forest system at Granta Pools and elsewhere in Tasmania (Fig. 5c). The first is related to the effect of reduced interception and transpiration on the hydrologic regime of the local non-forest vegetation system. Observations of increasingly waterlogged soils across forest-non-forest boundaries are common in highrainfall, oligotrophic Tasmania, with most authors invoking topography (Di Folco and Kirkpatrick 2011) and a reduced interception and transpiration in nonforest systems (Brown et al. 1982, Aabay and Berglund 1986, Bowman et al. 1986, Rumpff 2002, Di Folco 2007, 


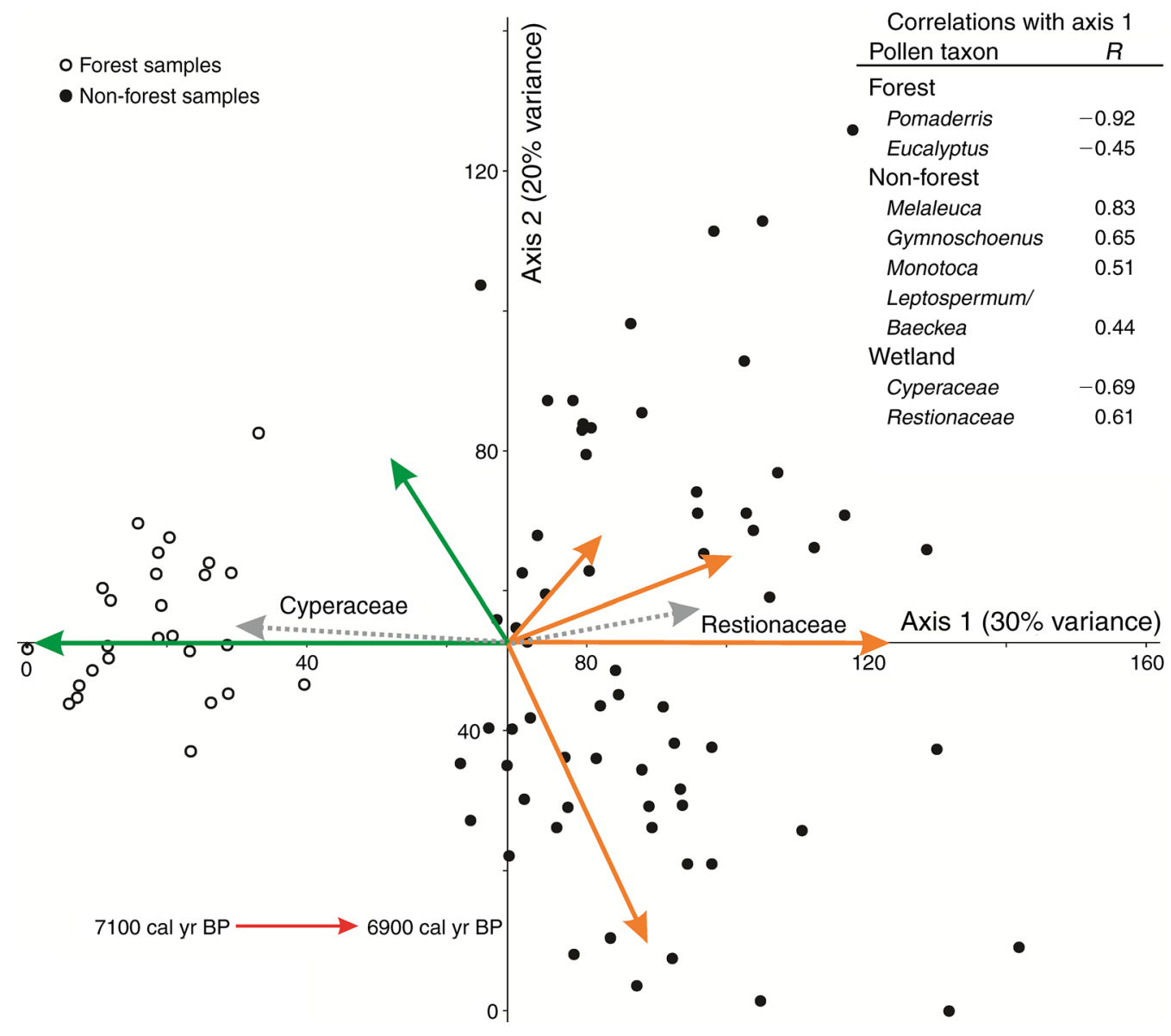

FIG. 4. Detrended correspondence analysis biplot of the terrestrial pollen data set from Granta Pools. The position of fossil samples is shown: open circles denote samples with a strong (negative) correlation to forest pollen taxa (green arrows pointing left); solid circles denote samples with a strong (positive) correlation to non-forest pollen taxa (orange arrows pointing right). The arrow length indicates the strength of the correlation, and the correlation statistics are listed. Dashed arrows indicate wetland taxa. The ages indicate the timing of the transition from forest to non-forest.

Wood et al. 2011) as key factors in this disparity. At Granta Pools, reduced transpiration rates due to the immediate replacement of trees by peat-forming wetland plants, rhizomatous sedges, and non-forest species tolerant of waterlogged soils (such as Melaleuca) may have amplified soil waterlogging in this local topographic depression, effectively precluding seedling establishment (sensu Díaz and Armesto 2007). The capacity for rhizomatous plants to endure, colonize, and dominate waterlogged terrain (Koncalov 1990) would act as a positive eco-hydrological feedback that effectively excludes tree establishment and facilitates maintenance of waterlogging at the site. Second, the dense sedge swards that dominate non-forest vegetation at Granta Pools ( $G$. sphaerocephalus) are likely to exclude trees through interspecific competition (Fensham and Kirkpatrick 1992). Field and pot experiments have demonstrated that the development of grass swards in open environments in Tasmania inhibits the establishment of trees by blanketing the ground, and if germination occurs, seedling growth is likely to be inhibited because the grass root mat imposes a physical barrier to root development (Fensham and Kirkpatrick 1992, Kube 1993).

\section{A catastrophic regime shift between alternative stable states?}

A call for an application of the alternative stable state theoretical framework to the vegetation landscape of the humid regions of Tasmania draws support from conceptual models (Jackson 1968, Bowman and Jackson 1981). It is also consistent with recent studies that provide tentative (Wood and Bowman 2012) and more speculative (Fletcher and Thomas 2010) evidence that forest and non-forest are alternative stable states in the landscape of western and southern Tasmania. The firedriven transition from forest to non-forest vegetation at Granta Pools, Tasmania, represents a clear example of a catastrophic regime shift. Catastrophic regime shifts occur when a regime threshold is crossed in 


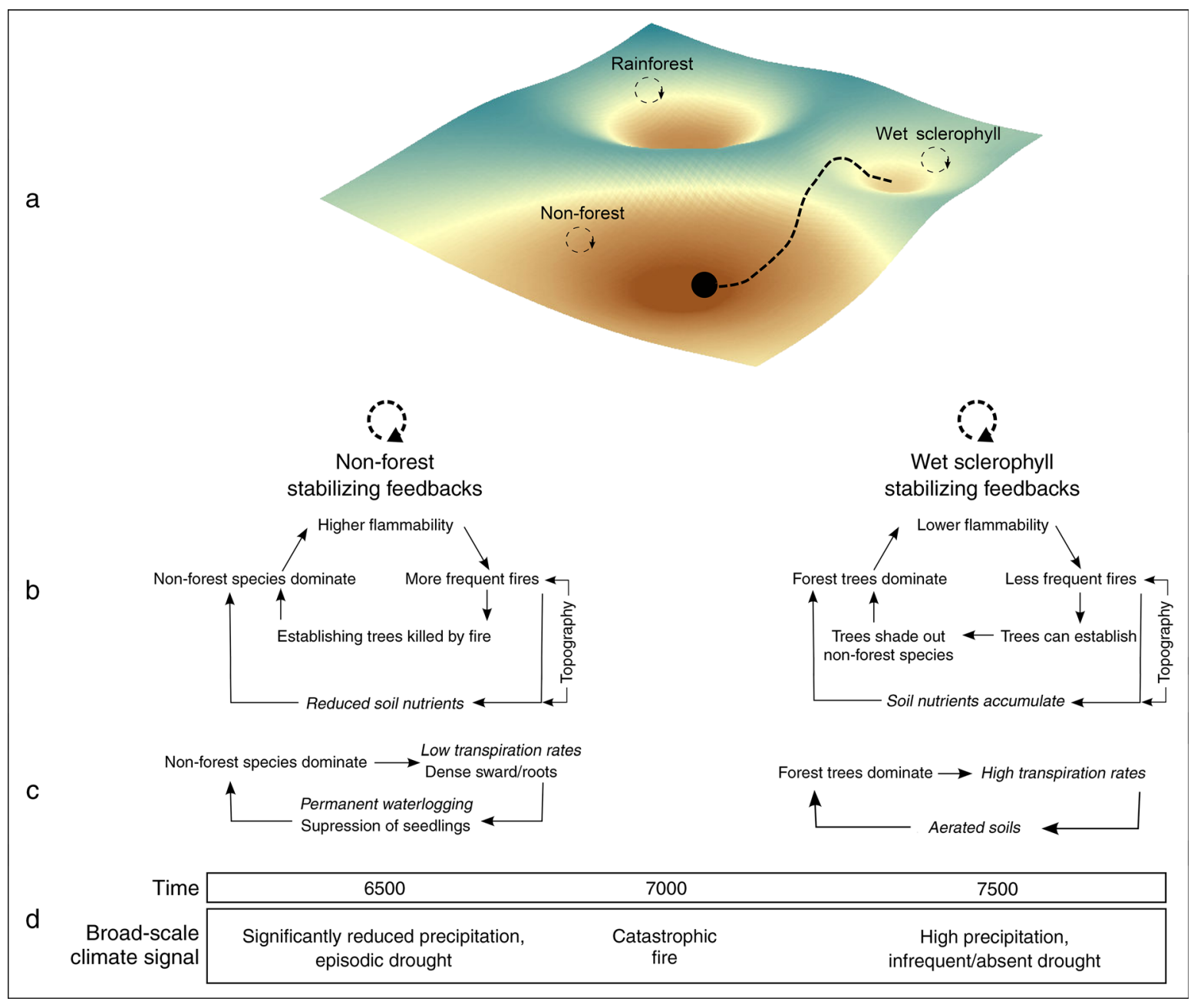

FIG. 5. A hypothetical stability landscape (sensu Scheffer et al. 2001) and proposed feedback mechanisms for the alternative stable states found in the humid landscape of Tasmania based on our interpretation of the Granta Pools data (sensu Wood and Bowman 2012). (a) A three-dimensional stability landscape that depicts rainforest and non-forest (moorland/scrub) as deep and resilient basins (with transitions into or out of these basins requiring strong environmental forcing) and temperate eucalypt (wet sclerophyll) forest as a shallower basin. The dashed line follows the trajectory of the Granta Pools (this study) vegetation system in response to a catastrophic fire. The position of the ball shows the vegetation state after this stochastic disturbance event, with the vegetation state now lying within the deep, stable, and resilient non-forest basin. (b and c) The self-regulating internal feedback mechanisms (symbolized by the dashed circles with arrows) maintaining stability within the forest and non-forest vegetation states: (b) those depicted by Wood and Bowman (2012) as operating in the landscape of southwest Tasmania and (c) those proposed as operating at Granta Pools. (d) A summary of the temporal sequence between 7500 and $6500 \mathrm{cal}$ yr BP that lead to the critical transition between a forest and non-forest vegetation state at Granta Pools following the stochastic fire event. Italic typeface indicates the proposed internal feedback mechanism for each stable state.

response to environmental forcing, and a system reorganizes around a new basin of attraction (Scheffer and Carpenter 2003). This type of response can be an artifact of a non-linear reaction to a gradual environmental change or a response to a stochastic event, such as fire. Within the alternative stable state paradigm, if a system has only one basin of attraction (stable state), it will follow a trajectory back toward that same state after a perturbation. If there are multiple basins of attraction (alternative stable states), a sufficiently severe event will force the system toward an alternative basin, and the system settles around an alternative stable state (Scheffer and Carpenter 2003). Such critical transitions are manifest on either side of a breakpoint in time-series data (Willis et al. 2010, Jeffers et al. 2011). Our time-series data of vegetation change at Granta Pools display a clear breakpoint at ca. $7000 \mathrm{cal}$ yr BP (Fig. 5b), coincident with maximum CHAR values that document a regime shift from a forest (temperate eucalypt forest) to a non-forest (moorland) basin of attraction in response to a stochastic fire episode (Figs. 4, 5). 


\section{On the problem of "origin"}

Broad-scale paleoecological studies of the Tasmanian forest-non-forest system argue that the application of fire after the arrival of people to a largely non-forested landscape through the last glacial stage essentially deflected post-glacial vegetation development toward species that could tolerate the altered fire regime and increasing humidity through the transition to the succeeding interglacial period (the Holocene): namely non-forest moorland species (Fletcher and Thomas 2010). Fletcher and Thomas (2010) further contend that the inherent flammability of non-forest vegetation in this region was sufficient to maintain non-forest dominance throughout the climatic vicissitudes of the Holocene to the present day. While this thesis may hold at the coarse spatiotemporal scale (landscape and millennial) afforded by their regional paleoecological synthesis, it is very likely that transitions between forest and non-forest occurred at smaller scales of space and time through the Holocene, resulting from, for example, stochastic fire events like those we have documented. Underpinning this notion, and indeed all attempts to account for the contemporary vegetation landscape of southwest Tasmania, is the widespread and untested assumption that fire is the key factor in the origin of this landscape mosaic. Importantly, our study is the only study to date that reveals fire as the causal factor leading to the establishment of non-forest vegetation in place of forest in Tasmania. The implication from our data that, once established, the self-maintenance of non-forest vegetation at Granta Pools is facilitated via eco-hydrological and eco-physical feedbacks, whilst in need of empirical data for conclusive support, is consistent with experimental and observational studies documenting the ecohydrological effects of forest removal (e.g., Tallis 1991, Díaz and Armesto 2007). Further, the implication that hydrology, rather than fire, was sufficient for selfmaintenance of the non-forest state corroborates the notion that self-maintenance pathways can vary from those that lead to the establishment of an alternative stable state (Drake 1991). Moreover, in potentially identifying both the origin and maintenance mechanisms of this system, we successfully address the concerns of those who require independent treatment of these key processes in order to validate the existence of alternative stable states (Petraitis and Latham 1999).

\section{CONClusion}

We have documented an unequivocal transition between forest and non-forest in the humid forestnon-forest landscape mosaic of Tasmania. Critically, we have identified different origin and maintenance pathways in this regime shift between alternative stable states. Initially, fire destroyed the then extant forest, opening the system to an invasion by a suite of nonforest plant species that altered the local hydrological and physical environment. The maintenance of the nonforest state for $\sim 7000$ years following the forest-non- forest transition occurs despite widely varying fireregimes, and we postulate that the maintenance of the non-forest state occurs via eco-hydrological and ecophysical feedbacks that differ from the origin (fire).

\section{ACKNOWLEDGMENTS}

M.-S. Fletcher was supported by ARC project DI110100019, Fondecyt project 3110180, and the Institute of Ecology and Biodiversity, Chile, through the life of this project. We thank Phil Roberts for assistance with charcoal analysis and Graeme Haberle for help in the field. We thank Bree Fletcher for assistance with laboratory work. We thank Ian Thomas for a fruitful discussion over the temporal dynamics of Tasmanian vegetation.

\section{Literature Cited}

Aabay, B., and B. E. Berglund. 1986. Characterization of peat and lake deposits. Pages 231-246 in B. E. Berglund and M. Ralska-Jasiewiczowa, editors. Handbook of Holocene palaeoecology and palaeohydrology. John Wiley and Sons, Wiltshire, UK.

Bowman, D. M. J. S., and W. D. Jackson. 1981. Vegetation succession in southwest Tasmania. Search 12:358-362.

Bowman, D. M. J. S., A. R. Maclean, and R. K. Crowden. 1986. Vegetation-soil relationships in the lowlands of southwest Tasmania. Australian Journal of Ecology 11:141-153.

Bowman, D. M. J. S., and S. W. Wood. 2009. Fire driven land cover change in Australia and W.D. Jackson's theory of the fire ecology of southwest Tasmania. Pages 87-111 in M. A. Cochrane, editor. Tropical fire ecology: climate change, land use and ecosystem dynamics. Springer-Praxis, Heidelberg, Germany.

Bradstock, R. A. 2010. A biogeographic model of fire regimes in Australia: current and future implications. Global Ecology and Biogeography 19:145-158.

Brown, M. J., R. K. Crowden, and S. J. Jarman. 1982. Vegetation of an alkaline pan-acidic peat mosaic in the Hardwood River Valley, Tasmania. Australian Journal of Ecology 7:3-12.

Bunting, M. J. 2003. Pollen-vegetation relationships in nonarboreal moorland taxa. Review of Palaeobotany and Palynology 125:285-298.

Casini, M., J. Hjelm, J.-C. Molinero, J. Lövgren, M. Cardinale, V. Bartolino, A. Belgrano, and G. Kornilovs. 2009. Trophic cascades promote threshold-like shifts in pelagic marine ecosystems. Proceedings of the National Academy of Sciences USA 106:197-202.

Connell, J. H., and W. P. Sousa. 1983. On the evidence needed to judge ecological stability or persistence. American Naturalist 121:789-824.

Di Folco, M. B. 2007. Tasmanian organic soils. University of Tasmania, Hobart, Australia.

Di Folco, M. B., and J. B. Kirkpatrick. 2011. Topographic variation in burning-induced loss of carbon from organic soils in Tasmanian moorlands. Catena 87:216-225.

Díaz, M., and J. Armesto. 2007. Physical and biotic constraints on tree regeneration in secondary shrublands of Chiloe Island, Chile. Revista Chilena de Historia Natural 80:13-26.

Drake, J. A. 1991. Community-assembly mechanics and the structure of an experimental species ensemble. American Naturalist 137(1):1-26.

Ellis, R. C., and I. Thomas. 1988. Pre-settlement and postsettlement vegetational change and probable Aboriginal influences in a highland forested area in Tasmania. Pages 199-216 in K. J. Frawley and N. M. Semple, editors. Australia's ever-changing forests: proceedings of the First National Conference on Australian Forest History. Department of Geography and Oceanography, Australian Defence Force Academy, Canberra, Australia. 
Faegri, K., and J. Iversen. 1989. Textbook of pollen analysis. Wiley, New York, New York, USA.

Fensham, R. J., and J. B. Kirkpatrick. 1992. The eucalypt forest-grassland/grassy woodland boundary in central Tasmania. Australian Journal of Botany 40:123-138.

Fletcher, M.-S., and I. Thomas. 2007. Modern pollenvegetation relationships in western Tasmania, Australia. Review of Palaeobotany and Palynology 146:146-168.

Fletcher, M.-S., and I. Thomas. 2010. The origin and temporal development of an ancient cultural landscape. Journal of Biogeography 37:2183-2196.

Higuera, P. E., L. B. Brubaker, P. M. Anderson, F. S. Hu, and T. A. Brown. 2009. Vegetation mediated the impacts of postglacial climate change on fire regimes in the south-central Brooks Range, Alaska. Ecological Monographs 79:201-219.

Higuera, P. E., D. G. Gavin, P. J. Bartlein, and D. J. Hallett. 2010. Peak detection in sediment-charcoal records: impacts of alternative data analysis methods on fire-history interpretations. International Journal of Wildland Fire 19:996-1014.

Hirota, M., M. Holmgren, E. H. Van Nes, and M. Scheffer. 2011. Global resilience of tropical forest and savanna to critical transitions. Science 334:232-235.

Jackson, W. D. 1968. Fire, air, water and earth - an elemental ecology of Tasmania. Proceedings of the Ecological Society of Australia 3:9-16.

Jeffers, E. S., M. B. Bonsall, S. J. Brooks, and K. J. Willis. 2011. Abrupt environmental changes drive shifts in tree-grass interaction outcomes. Journal of Ecology 99:1063-1070.

Koncalov, H. 1990. Anatomical adaptations to waterlogging in roots of wetland graminoids: limitations and drawbacks. Aquatic Botany 38:127-134.

Kube, P. 1993. Establishment techniques and early growth of eucalypt seedlings on a high elevation grass site in Tasmania. Tasforests 5:63-75.

Macphail, M. K. 1979. Vegetation and climates in southern Tasmania since the last glaciation. Quaternary Research 11: 306-341.

Macphail, M. K. 1984. Small-scale dynamics in and early Holocene wet sclerophyll forest in Tasmania. New Phytologist 96(1):131-147.

Mayer, A. L., and A. H. Khalyani. 2011. Grass trumps trees with fire. Science 334:188-189.

McCormac, F. G., A. G. Hogg, P. G. Blackwell, C. E. Buck, T. F. G. Higham, and P. J. Reimer. 2004. SHCal04 Southern Hemisphere calibration, 0-11.0 cal kyr BP. Radiocarbon 46: 1087-1092.

McCune, B., and M. J. Mefford. 1999. PC-Ord for Windows. MjM Software, Gleneden Beach, Oregon, USA.

Odion, D. C., M. A. Moritz, and D. A. DellaSala. 2010. Alternative community states maintained by fire in the Klamath Mountains, USA. Journal of Ecology 98:96-105.

Pemberton, M. 1989. Land systems of Tasmania (south west). Tasmanian Government Printer, Hobart, Australia.

Peterson, C. H. 1984. Does a rigorous criterion for environmental identity preclude the existence of multiple stable points? American Naturalist 124:127-133.

Petraitis, P. S., and S. R. Dudgeon. 2004. Detection of alternative stable states in marine communities. Journal of Experimental Marine Biology and Ecology 300:343-371.
Petraitis, P. S., and R. E. Latham. 1999. The importance of scale in testing the origins of alternative community states. Ecology 80:429-442.

Pyrke, A. F., and J. B. Marsden-Smedley. 2005. Fire-attributes categories, fire sensitivity, and flammability of Tasmanian vegetation communities. Tasforests 16:35-46.

Rumpff, L. 2002. Chickens or eggs? The nature of the edaphic influence on vegetation succession in Tasmania. University of Melbourne, Melbourne, Australia.

Scheffer, M., S. Carpenter, J. A. Foley, C. Folke, and B. Walker. 2001. Catastrophic shifts in ecosystems. Nature 413: 591-596.

Scheffer, M., and S. R. Carpenter. 2003. Catastrophic regime shifts in ecosystems: linking theory to observation. Trends in Ecology and Evolution 18:648-656.

Scheffer, M., S. Hosper, M. Meijer, B. Moss, and E. Jeppesen. 1993. Alternative equilibria in shallow lakes. Trends in Ecology and Evolution 8:275-279.

Schröder, A., L. Persson, and A. M. De Roos. 2005. Direct experimental evidence for alternative stable states: a review. Oikos 110:3-19.

Sharma, M. L. 1984. Evapotranspiration from a eucalyptus community. Agricultural Water Management 8:41-56.

Tallis, J. 1991. Forest and moorland in the South Pennine Uplands in the mid-Flandrian period: III. The spread of moorland-local, regional and national. Journal of Ecology 79:401-415.

Warman, L., and A. T. Moles. 2009. Alternative stable states in Australia's wet tropics: a theoretical framework for the field data and a field-case for the theory. Landscape Ecology 24:113.

Webb, J., I. Thomas, and K. Thiele. 1994. The physical setting of the Gog Range. Pages 39-51 in A. Sagona, editor. Bruising the red earth: ochre mining and ritual in aboriginal Australia. Melbourne University Press, Melbourne, Australia.

Whitlock, C., and C. P. S. Larsen. 2001. Charcoal as a fire proxy. Tracking environmental change using lake sediments. Kluwer Academic, Dordrecht, The Netherlands.

Willis, K., R. Bailey, S. Bhagwat, and H. Birks. 2010. Biodiversity baselines, thresholds and resilience: testing predictions and assumptions using palaeoecological data. Trends in Ecology and Evolution 25:583-591.

Wilson, J. B., and A. D. Agnew. 1992. Positive-feedback switches in plant communities. Pages 264-321 in M. Begon and A. H. Fitter, editors. Advances in ecological research. Volume 23. Academic Press, London, UK.

Wood, S. W., and D. M. J. S. Bowman. 2012. Alternative stable states and the role of fire-vegetation-soil feedbacks in the temperate wilderness of southwest Tasmania. Landscape Ecology 27(1):13-28.

Wood, S. W., Q. Hua, and D. M. J. S. Bowman. 2011. Firepatterned vegetation and the development of organic soils in the lowland vegetation mosaics of south-west Tasmania. Australian Journal of Botany 59:126-136.

Woodward, N., D. Gray, and C. Elliott. 1993. Repeated Palaeozoic thrusting and allochthoneity of Precambrian basement, northern Tasmania. Australian Journal of Earth Sciences 40:297-311. 